\title{
Análise dos custos de produção dos agentes biológicos para controle de diatraea saccharalis em cana-de-açúcar: Um estudo de caso em laboratório de produção massal
}

\begin{abstract}
Paulo Arnaldo Olak
Doutorado em Controladoria e Contabilidade pela Universidade de São Paulo -

FEA/USP

Professor da Universidade Estadual de Londrina - UEL

Rodovia Celso Garcia Cid, PR 445 Km 380. Campus Universitário. Londrina/PR. CEP:

86057-970

E-mail: olak@uel.br

Joice Amarante

Pós-graduação em Contabilidade e Controladoria Empresarial pela Universidade

Estadual de Londrina - UEL

Rodovia Celso Garcia Cid - Pr 445 Km 380, s/n. Campus Universitário. Londrina/PR.

CEP: 86057-970

Analista Contábil de empresa de Comércio e Construção Civil

E-mail: joice_amt@hotmail.com
\end{abstract}

\section{RESUMO}

O presente artigo apresenta uma análise dos custos de produção do parasitóide Cotesia flavipes utilizado como controle biológico da Diatraea saccharalis, conhecida como broca da cana-de-açúcar, partindo do acompanhamento da produção e analisando cada etapa do processo, ou seja, os processos subdivididos em departamentos. O estudo foi realizado em um laboratório de produção massal de Cotesia flavipes localizado na região do Vale Paranapanema, no qual se pode acompanhar e coletar todas as informações do processo para formação e análise dos custos. Para realização desta pesquisa utilizou-se o método de Custeio $A B C$, identificando cada etapa do processo alocando-as em departamentos, formando assim o custo de cada um. No estudo se levou em consideração apenas os custos com mãode-obra e materiais. Após levantamento dos custos de cada departamento, constatouse que o maior consumo é de serviços, ou seja, mão-de-obra, responsável por $67 \%$ dos custos totais e apenas $33 \%$ dos custos são de materiais. O departamento com maior consumo de materiais é o da Dieta, responsável por $86 \%$ do custo total de materiais e o departamento de Inoculação da Broca é responsável por $60 \%$ dos recursos totais com mão-de-obra. Com a apuração de todos os dados levantados, chegou-se à conclusão que cada copo dentro do processo custou para a empresa $R \$$ 1,94 , ou seja, $\mathrm{R} \$ 0,06$ por massa de pupa.

Palavras-chave: Custos de Produção. Custeio ABC. Cotesia Flavipes. Broca da canade-açúcar. 
Análise dos custos de produção dos agentes biológicos para controle de diatraea saccharalis em cana-de-açúcar: Um estudo de caso em laboratório de produção massal

Paulo Arnaldo Olak, Joice Amarante

\section{ABSTRACT}

This paper presents an analysis of costs production of the parasitoid cotesia flavipes used as biological control of $D$. saccharalis, known as drill cane sugar, starting from the production monitoring and analyzing each step of the process, ie, the processes subdivided into departments. The study was conducted in a mass production \of laboratory Cotesia flavipes located in the Vale Paranapanema region, in which there was possible to monitor and collect all the process information for determining and analyzing the costs. For this research we used the $A B C$ costing method, identifying every step of allocating them into departments, thus forming the cost of each. In the study we consider only the cost of hand labor and materials. After a survey of the costs of each department, it was found that the highest consumption is services, ie, hand labor, accounted for $67 \%$ of total costs and only $33 \%$ of costs are from material. The department with increased consumption of materials is the diet, accounting for $86 \%$ of the total cost of materials and the inoculation department drill accounts for $60 \%$ of total resources with hand labor. With the determination of all the data collected, reached the conclusion that each cup of the process cost US $\$ 1.94$ for the company, or US $\$ 0.06$ per mass pupa.

Keywords: Production Costs. Costing ABC. Cotesia flavipes. Drill cane sugar.

\section{INTRODUÇÃO}

No Brasil, grandes áreas são destinadas, atualmente, ao cultivo da cana-deaçúcar, com uma produção realizada em 2011 de 479,35 milhões de toneladas na região centro-sul (UNICA, 2012). Portanto, são investidos grandes recursos relacionados à tecnologia agrícola e industrial em toda cadeia produtiva, incluindo o controle biológico da praga da cana-de-açúcar, pois o ataque de pragas, como a Diatraea saccharalis, conhecida como broca da cana-de-açúcar, resulta também em altos custos na produção final da cana, levando a grandes prejuízos em determinados casos. Sendo assim, medidas vão sendo desenvolvidas para controle das mesmas, ou seja, o controle biológico.

Este controle biológico é realizado através de vespas endoparasitoides conhecidas como Cotesia flavipes. Com sua produção em laboratório é permitido aos engenheiros maior disponibilidade de materiais. A análise começa no campo, verificando-se a proporção de infestação da praga, sendo assim são destinadas 
Análise dos custos de produção dos agentes biológicos para controle de diatraea saccharalis em cana-de-açúcar: Um estudo de caso em laboratório de produção massal

Paulo Arnaldo Olak, Joice Amarante

quantidades proporcionais, à infestação da broca da cana-de-açúcar, de Cotesia flavipes para eventual liberação e consequentemente controle da praga.

A produção de Cotesia flavipes no laboratório torna-se uma cadeia, pois primeiramente é necessário produzir a própria praga (broca da cana-de-açúcar) e após a inoculação da mesma tornam-se as "vespinhas".

Destaca-se como grande importância desta pesquisa a contribuição para o crescimento da produção de Cotesia flavipes, entende-se que para o empreendedor, que possui um laboratório de produção de Cotesia flavipes, é um negócio viável, pois em regiões com grande produção de cana-de-açúcar, os produtores da cultura necessitarão de muitos agentes biológicos (Cotesia flavipes) para controle da broca da cana-de-açúcar e nada melhor do que além ter o produto disponível para atender a demanda do mercado se tenha um controle funcional de formação de custos e preços para que assim não ocorram problemas com controle, visando sempre o crescimento do negócio junto aos fornecedores.

Uma das maiores dificuldades encontrados para análise dos custos de produção da Cotesia Flavipes, são as poucas informações já estudadas anteriormente, pois poucos são os materiais de acesso a este tipo de controle, as pesquisas já desenvolvidas têm como foco a perca de produção da cana-de-açúcar devido ao ataque da broca, mas nada que se relacione ao processo produtivo da produção do melhor controle já encontrado para controle desta praga.

A Contabilidade de Custos é um sistema de informações inserido à Contabilidade que tem como principais ferramentas o medir o desempenho administrativo e operacional, estando diretamente relacionada com o planejamento, orçamento e controle, tendo como finalidade encontrar mecanismos para redução de gastos, controles de despesas e contribuição para as devidas tomadas de decisões, ou seja, a solução de problemas.

Com base no contexto apresentado, formula-se a seguinte questão orientadora desta pesquisa: Qual o custo de produção de agentes biológicos para controle de Diatraea saccharalis no cultivo da cana-de-açúcar? Portanto, o estudo tem como 
Análise dos custos de produção dos agentes biológicos para controle de diatraea saccharalis em cana-de-açúcar: Um estudo de caso em laboratório de produção massal

Paulo Arnaldo Olak, Joice Amarante

objetivo geral identificar e analisar os custos de produção de agentes biológicos para controle de Diatraea saccharalis no cultivo da cana-de-açúcar

O artigo está estruturado em sete capítulos. Nesta parte introdutória são apresentados o contexto, o problema da pesquisa e o objetivo. Nos capítulos 2 a 4 fazse a revisão da bibliografia, iniciando com processo de gestão, custos para tomada de decisões e cana-de-açúcar, processos e os custos do controle de pragas. No capítulo 5 apresentam-se os procedimentos metodológicos utilizados; no capítulo 6 são apresentados e analisados os dados obtidos no estudo; e no capítulo 7 constam as considerações finais, seguidas das referências.

\section{PROCESSO DE GESTÃO}

\subsection{Conceito e Fases do Processo de Gestão}

Para Nakagawa (1993, p. 39) "gestão é a atividade de se conduzir uma empresa ao atingimento do resultado desejado por ela, apesar das dificuldades". Catelli (2009, p.58) corrobora esse pensamento, mencionando que "o processo de gestão deve assegurar que a dinâmica das decisões tomadas na empresa conduza-a efetivamente ao cumprimento de sua missão, garantindo-Ihe a adaptabilidade e o equilíbrio necessários para sua continuidade".

Catelli (2009, p. 58) ressalta que o processo de gestão deve:

- Ser estruturado com base na lógica do processo decisório;

- Contemplar, analiticamente, as fases de planejamento, execução e controle das atividades da empresa;

- Ser suportado por sistemas de informações que subsidiem as decisões que ocorrem em cada uma dessas fases.

Para Figueiredo e Caggiano (2008, p. 27) o processo de gestão possui cinco funções principais: Planejamento, Organização, Controle, Comunicação e Motivação. 
Análise dos custos de produção dos agentes biológicos para controle de diatraea saccharalis em cana-de-açúcar: Um estudo de caso em laboratório de produção massal

Paulo Arnaldo Olak, Joice Amarante

- Planejamento: [...] é um aperfeiçoamento na qualidade do processo decisório por uma cuidadosa consideração de todos os fatores relevantes, antes de a decisão ser tomada em conformidade com uma estratégia racional, segundo a qual o futuro da empresa deve ser orientado.

- Organização: envolve a definição da estrutura administrativa para que as decisões sejam implementadas. A configuração da área administrativa procura estabelecer a estrutura e a forma da organização e definir as responsabilidades e linhas de autoridade. Isso envolve definição das tarefas necessárias para alcançar as metas estratégicas, uma determinação de quem irá desempenhar estas tarefas e assumir responsabilidades por seu desempenho.

- Controle: é um sistema de feedback que possibilita aos desempenhos serem comparados com os objetivos planejados. O controle é um eficiente sistema de informações que revela a necessidade de ações corretivas em tempo apropriado, possibilitando aos gestores julgar se seu plano ainda é apropriado, diante das mudanças.

- Comunicação: é uma troca de fatos, idéias e opiniões [...]. Supõe uma ligação de todas as funções gerenciais pela transmissão e instruções internas da organização.

- Motivação: é o envolvimento total dos membros da organização e a busca de maneiras de como melhorar a performance individual.

\subsection{Planejamento Operacional}

Segundo Catelli (2009, p. 140) "planejamento operacional consiste na identificação, integração e avaliação de alternativas de ação e na escolha de um plano de ação a ser implementado". Para Nakagawa (1993, p. 52), "planejamento operacional define os planos, políticas e objetivos operacionais da empresa e tem como produto final o orçamento operacional [...]".

Andrade (2007) explica que o planejamento operacional está relacionado à definição de um plano detalhado e quantitativo referente às áreas funcionais, ou seja, produção, finanças, marketing e recursos humanos, especificando como as metas de curto prazo serão atingidas, bem como os procedimentos para administrar as operações diárias. 
Análise dos custos de produção dos agentes biológicos para controle de diatraea saccharalis em cana-de-açúcar: Um estudo de caso em laboratório de produção massal

Paulo Arnaldo Olak, Joice Amarante

Deve-se ressaltar a grande importância do planejamento operacional, pois este não deve ser desenvolvido apenas para o curto prazo, pois os acontecimentos diários mesmo sendo administrados, podem ocasionar sérios desvios. Sendo assim, aconselha-se que o planejamento operacional seja desenvolvido para o médio e longo prazo.

De acordo com Catelli (2009, p. 143) o planejamento operacional subdivide-se em:

- Pré-planejamento operacional: corresponde à fixação de objetivos, identificação das alternativas de ação e escolha das melhores alternativas que viabilizem as diretrizes estratégicas;

- Planejamento Operacional - médio e longo prazo: corresponde ao detalhamento das alternativas selecionadas, dentro de determinada perspectiva temporal considerada pela empresa como médio e longo prazos, quantificando-se analiticamente recursos, volumes, preços, prazos, investimentos e demais variáveis planejadas;

- Planejamento operacional - curto prazo: corresponde a um replanejamento efetuado em momento mais próximo a realização dos eventos e à luz do conhecimento mais seguro das variáveis envolvidas.

Nakagawa (1993, p.52) aduz que "a avaliação e a aprovação de planos, contam com o suporte e o apoio do sistema de informação do orçamento". Jiambalvo (2009, p. 280) explica que "os orçamentos são documentos formais que mensuram os planos de uma empresa para que ela possa alcançar seus objetivos". Em muitas empresas o processo de planejamento e controle nasce a partir do orçamento, pois é ele quem define os meios para se chegar aos objetivos.

Quando ocorre a compatibilização entre as informações geradas pelo sistema de informação e o modelo de decisão dos gerentes, os relatórios de avaliação de desempenho do sistema contábil durante a fase de execução dos planos aprovados, darão aos gerentes condições de tomarem decisões eficazes em suas respectivas áreas de responsabilidade. Sendo assim, os somatórios dos resultados de todas as 
Análise dos custos de produção dos agentes biológicos para controle de diatraea saccharalis em cana-de-açúcar: Um estudo de caso em laboratório de produção massal

Paulo Arnaldo Olak, Joice Amarante

áreas levarão a empresa como um todo a cumprir sua missão e propósitos básicos. (NAKAGAWA, 1993).

\subsection{Planejamento e Gestão do Lucro}

"Planeja-se porque existem tarefas a cumprir, atividades a desempenhar, enfim, produtos a fabricar, serviços a prestar. Deseja-se fazer isso da forma mais econômica possível, coordenando o uso de diversos recursos [...]" (CATELLI, 2009, p. 155).

O planejamento deve ser elaborado com clareza e objetividade e também nunca ser otimista demais, a empresa deve manter os "pés no chão". Assim, planejar com incertezas é necessário, pois não se sabe como será o cenário no decorrer dos períodos futuros. "Planejar diz respeito a conhecer a realidade e agir de acordo com esse conhecimento para se conseguir o que deseja" (CATELLI, 2009, p.156).

Para Andrade (2007), planejar significa desenvolver um programa para realização de objetivos e metas organizacionais. Este programa primeiramente envolve a escolha de uma ação, com a decisão dos gerentes traçando metas e objetivos em relação ao que se deverá fazer, determinando quando e como tal projeto será realizado.

Para Catelli (2009, p. 157),

Em todas as fases do processo de planejamento são tomadas decisões de diferentes tipos e amplitudes: desde as decisões estratégicas sobre quais seriam os grandes caminhos a serem trilhados, passando pelas decisões operacionais sobre o que deve ser feito, quando deverá ser feito, como deverá ser feito e quem deverá fazê-lo, até as decisões de controle, que tem por objetivo assegurar que os desvios sejam corrigidos e o plano alcançado.

Dentro de um processo de planejamento o desenvolvimento de um orçamento é extremamente importante, pois segundo Jiambalvo (2009, p. 281) "intensifica a comunicação e a coordenação". A realização de um orçamento exige clareza e 
Análise dos custos de produção dos agentes biológicos para controle de diatraea saccharalis em cana-de-açúcar: Um estudo de caso em laboratório de produção massal

Paulo Arnaldo Olak, Joice Amarante

objetividade para auxiliar em todo o planejamento forçando aos gestores refletirem sobre suas metas, objetivos e meios possíveis para alcançá-los.

Para Guerreiro (2006) a base conceitual para a gestão do lucro leva em consideração que não existe lucro por produto, porque não existe custo fixo por produto. E que o lucro está intimamente ligado à capacidade instalada da empresa, ou seja, quanto maior o volume de ativos operacionais disponíveis, maior deverá ser o lucro.

\subsection{Processo Produtivo}

Bonato (2004) entende que tanto o processo produtivo como o processo administrativo devem incorporar a qualidade, visando obter a qualidade da empresa como um todo e não somente do produto final.

O "consumidor" final é muito exigente em relação aos produtos que irão consumir, sendo assim, como citado pelo autor acima, o processo de produção deve garantir a qualidade do produto desde o início da produção e por todo o processo e não apenas dar um acabamento perfeito dizendo que o produto é excelente, pois após a primeira compra e checagem de que o produto não era tudo o que se esperava certamente o cliente não retornará a comprar o mesmo produto.

Para Hammer (2001 apud MATOS,2009), durante a fase de organização de processos, alguns princípios devem ser seguidos:

- Cada processo deve ser projetado como uma unidade com sua organização feita do início ao fim;

- Nenhuma atividade deve ser executada mais de uma vez, ou seja, não se deve tolerar duplicação e redundância de atividades; e

- O processo deve ser realizado por quem esteja mais bem preparado para fazê-lo, devendo verificar quem é a melhor pessoa ou até mesmo outra empresa para fazer a atividade.

Rummler e Brache (1994 apud MATOS, 2009) destacam o papel das pessoas no processo e salienta que de nada serve um processo com objetivos claros, se o 
Análise dos custos de produção dos agentes biológicos para controle de diatraea saccharalis em cana-de-açúcar: Um estudo de caso em laboratório de produção massal

Paulo Arnaldo Olak, Joice Amarante

elemento humano envolvido não está treinado ou preparado para fazer com que o processo seja executado eficientemente.

É muito comum deparar-se com colaboradores, principalmente na área de serviços, que não estão suficientemente preparados para a execução de tal função. Nesse caso, acredita-se que as empresas devam investir um pouco mais em capacitação de pessoal e até mesmo realizar testes averiguando que 0 trabalho realmente é adequado a cada solicitação.

\section{CUSTOS PARA TOMADA DE DECISÕES}

\subsection{Conceitos}

A contabilidade de custos surgiu na Revolução Industrial e está se transformando em um verdadeiro sistema de informação. Muitos são os métodos de custeio, sendo assim cabe ao controller da empresa a decisão de escolher o melhor método a ser utilizado de acordo com a atividade da empresa.

Para Leone (2009, p. 5),

A Contabilidade de Custos sendo o ramo da Contabilidade que se destina a produzir informações para os diversos níveis gerenciais de uma entidade, como auxilio às funções de determinação de desempenho, de planejamento e controle das operações e de tomada de decisões.

A contabilidade de custos acumula, organiza, analisa e interpreta os dados operacionais, físicos e os indicadores combinados no sentido de produzir relatórios com as informações de custos solicitadas (LEONE, 2009). É integrante direta da contabilidade financeira, sendo muito difícil dissociar uma da outra, tornando-se um instrumento poderoso, utilizando-se em seu desenvolvimento os princípios, os critérios e os procedimentos fundamentais da ciência contábil (LEONE, 2009). 
Análise dos custos de produção dos agentes biológicos para controle de diatraea saccharalis em cana-de-açúcar: Um estudo de caso em laboratório de produção massal

Paulo Arnaldo Olak, Joice Amarante

Nakagawa (1991, p. 79) explica que a utilização da informação sobre os custos está diretamente relacionada com a correta apropriação de custos, para fins de elaboração de relatórios gerenciais. Martins (2008, p.21) ressalta que:

A Contabilidade de Custos tem duas funções relevantes: o auxílio ao controle e a ajuda às tomadas de decisões. No que diz respeito ao controle, sua mais importante missão é fornecer dados para o estabelecimento de padrões, orçamentos e outras formas de previsão e, num estágio imediatamente seguinte, acompanhar o efetivamente acontecido para comparação com os valores anteriormente definidos.

Informações baseadas em suposições, em relação aos custos, trarão informações distorcidas e levarão os gestores a tomarem decisões ineficazes, resultando assim em futuros resultados não muito positivos. Para Megliorini (2007), os custos correspondem à parcela dos gastos consumida no ambiente fabril para a fabricação do produto, pela aquisição de mercadorias para revenda e para a realização de serviços. Sendo assim, conclui-se que o aperfeiçoamento na apropriação de custos é algo que se obtém determinando as relações de causa e efeito entre as atividades e o custeio de produtos, que é um dos objetivos dos relatórios gerenciais (NAKAGAWA, 1991).

\subsection{Custos e Processos Produtivos}

Segundo Leone (2009, p. 29) "os custos de produção são definidos, organizados e analisados por meio de muitas abordagens". Para o autor, um processo de produção exige que se entendam algumas definições. Portanto, conclui-se que custos de produção são todos os custos ligados diretamente à produção dos produtos, onde: (a) material direto é o custo de todos os materiais; (b) mão-de-obra direta é o custo da mão-de-obra diretamente associada à produção; e (c) custos indiretos de produção são todos os demais custos da fabricação, formando assim o custo do produto. 
Análise dos custos de produção dos agentes biológicos para controle de diatraea saccharalis em cana-de-açúcar: Um estudo de caso em laboratório de produção massal

Paulo Arnaldo Olak, Joice Amarante

O roteiro de fabricação compreende uma discriminação detalhada do processo para cada item do produto até o produto final, dentro de uma sequência lógica, saindo das matérias-primas, formando os subconjuntos, depois os conjuntos, até a montagem do produto final. Em resumo, o roteiro de fabricação diz quais são as tarefas e etapas para se fazer o produto e como elas devem ser desenvolvidas. (PADOVEZE, 2009).

Jiambalvo (2009, p. 159) explica que

As empresas alocam seus custos aos seus produtos por quatro razões principais: para obter informações necessárias para uma tomada de decisões adequadas; para reduzir o uso trivial de recursos em comum; para incentivar os gerentes a avaliarem a eficiência dos serviços prestados internamente e para calcular o "custo total" dos produtos com vistas à geração de relatórios financeiros e à determinação de preços com base nos custos.

Para melhor compreensão pode-se observar no Quadro 1 algumas das terminologias relacionadas à contabilidade de custos.

\begin{tabular}{|c|c|}
\hline Terminologia & Especificação \\
\hline Gastos & $\begin{array}{c}\text { São todos os esforços financeiros que as organizações fazem para obter } \\
\text { bens ou serviços, geralmente feitos na forma de entrega ou promessa de } \\
\text { entrega de dinheiro. }\end{array}$ \\
\hline Investimentos & $\begin{array}{l}\text { São gastos realizados para a melhoria ou prolongamento de vida útil de } \\
\text { "antigas" máquinas e equipamentos visando benefícios futuros. }\end{array}$ \\
\hline Custos & $\begin{array}{l}\text { Gastos relativos a bens e serviços utilizados na produção de outros bens e } \\
\text { serviços }\end{array}$ \\
\hline Despesas & $\begin{array}{c}\text { Bens ou serviços consumidos direta ou indiretamente para a obtenção de } \\
\text { receitas }\end{array}$ \\
\hline Desembolso & Pagamento resultante da aquisição de bens ou serviços \\
\hline Perda & $\begin{array}{c}\text { Ocorrem quando bens ou serviços são consumidos de forma anormal ou } \\
\text { involuntária. }\end{array}$ \\
\hline
\end{tabular}

Quadro 1: Terminologias Aplicadas à Contabilidade de Custos Fonte: Adaptado de Martins (2008, p. 25).

\subsection{O uso do Custo de Oportunidade para a Tomada de Decisões}

O resultado que todo empresário espera com o processo de levantamento de custos nada mais é do que ter informações suficientes para as devidas tomadas de 
Análise dos custos de produção dos agentes biológicos para controle de diatraea saccharalis em cana-de-açúcar: Um estudo de caso em laboratório de produção massal

Paulo Arnaldo Olak, Joice Amarante

decisões, portanto, leva-se em consideração neste tópico o custo de oportunidade, que permite observar qual a melhor estratégia a seguir, entre duas ou mais alternativas.

Toda vez que existirem problemas de escolha entre várias alternativas de ação, estará presente o conceito de custo de oportunidade. Quando se analisam várias alternativas de decisão, o decisor sempre se perguntará se o benefício a ser obtido, em relação ao sacrifício de recursos correspondentes, será o melhor possível nas circunstâncias em que a decisão está sendo tomada (MARTINS, 2008).

Leone (2009, p. 46) explica que "custo de oportunidade representa simplesmente hipótese. Os custos de oportunidade representam vantagens perdidas, medidas monetariamente relacionadas à segunda melhor alternativa rejeitada". A maneira mais adequada de se trabalhar utilizando o custo de oportunidade é antes mesmo de tomar toda e qualquer decisão verificar quais as oportunidades, ou seja, quais hipóteses existem perante determinado projeto. Portanto após levantamento dos mesmos deve-se analisar qual seria a melhor opção para a empresa, evidenciando qual ação deverá ser aceita.

O custo de oportunidade para Horngren (1986 apud BEUREN, 1993), é o sacrifício calculado em função da rejeição de uma alternativa; é o valor máximo do sacrifício decorrente do abandono de uma alternativa; é o lucro máximo que poderia se obter caso o bem ou serviço tivesse sido aplicado a outro uso operacional.

\subsection{Custeio Baseado em Atividades (ABC)}

$O$ custeio baseado em atividades ( $A B C$ ) nasceu nos Estados Unidos em meados da década de 1980. É um sistema de análise de custos que tem como objetivo reduzir as distorções provocadas pelo rateio dos custos indiretos de fabricação (MARTINS, 2008)

Para Crepaldi (2008, p. 224), 
Análise dos custos de produção dos agentes biológicos para controle de diatraea saccharalis em cana-de-açúcar: Um estudo de caso em laboratório de produção massal

Paulo Arnaldo Olak, Joice Amarante

O ABC permite uma análise de custos através das atividades da empresa. Cada atividade descreve o que a empresa faz e quanto de recursos ela utiliza para fabricar seus produtos. A metodologia de custeio $A B C$ identifica as atividades desenvolvidas em uma empresa e determina seu custo e desempenho.

Megliorini (2007) assinala que a primeira etapa do sistema de custeio ABC é identificar as atividades executadas em cada departamento. As atividades podem ser trabalhos específicos realizados com o objetivo de converter recursos em produtos.

A produção do parasitóide Cotesia flavipes, por exemplo, conta com diversos departamentos, sendo distinta a função executada entre uma atividade e outra, alocando-se corretamente o que cada atividade consome perante o custo total de produção.

Para Martins (2008, p. 286) a análise de custos está sob duas visões:

A visão econômica de custeio, que é uma visão vertical, no sentido de que apropria os custos aos objetos de custeio através das atividades realizadas em cada departamento e a visão de aperfeiçoamento de processos, que é uma visão horizontal, no sentido de que capta os custos dos processos através das atividades realizadas nos vários departamentos funcionais.

Martins (2008, p. 294) ainda conclui que:

Uma vez que os processos são compostos por atividades que se interrelacionam, tal análise permite uma visualização das atividades que podem ser melhoradas, reestruturadas ou até mesmo eliminadas dentro de um processo, de forma a melhorar o desempenho competitivo da empresa.

Sendo assim, compreende-se que primeiramente são identificadas as atividades e em seqüência os custos das atividades aos produtos produzidos. A escolha dos direcionadores de custos é o grande diferencial do sistema de custeio $\mathrm{ABC}$. 
Análise dos custos de produção dos agentes biológicos para controle de diatraea saccharalis em cana-de-açúcar: Um estudo de caso em laboratório de produção massal

Paulo Arnaldo Olak, Joice Amarante

Martins (2008, p. 96) explica que

Direcionador de custos é o fator que determina o custo de uma atividade [...]. Para efeito de custeio de produtos, o direcionador deve ser o fator que determina ou influencia a maneira de como os produtos "consomem" as atividades. Assim, o direcionador de custos será a base utilizada para atribuir os custos das atividades aos produtos.

As atividades desenvolvidas dentro de uma organização podem ser classificadas em primárias e secundárias. O espaço ocupado (departamento) por atividades produtivas é considerado como atividade primária. As atividades executadas dentro de um departamento para apoiar as atividades primárias são caracterizadas como sendo secundárias (BOTELHO, 2004).

Esta análise que o sistema de custeio $A B C$ permite ao controller da empresa contribui de forma significativa para o crescimento da empresa, pois há a possibilidade de visualização de quais departamentos podem estar apresentando consumos exagerados e quais as atividades que ainda necessitam de recursos para sua manutenção, sendo este um dos principais motivos em se adotar este método para 0 estudo nessa pesquisa.

\section{CANA-DE-AÇÚCAR, PROCESSOS E OS CUSTOS DO CONTROLE DE PRAGAS}

\subsection{Cana-de-açúcar}

A cana-de-açúcar é cultivada nas regiões centro-sul e norte-nordeste do Brasil, com período de safra de abril a novembro e setembro a março, respectivamente (COSAN, 2009).

De acordo com Cosan (2009), 

Análise dos custos de produção dos agentes biológicos para controle de diatraea saccharalis
em cana-de-açúcar: Um estudo de caso em laboratório de produção massal

Paulo Arnaldo Olak, Joice Amarante

Os maiores consumidores de açúcar do mundo são tipicamente também os maiores produtores do mundo, sendo os cinco principais países produtores responsáveis por $59 \%$ da produção mundial de açúcar. O Brasil é o maior produtor [e também exportador] de açúcar, com participação de aproximadamente $21 \%$ da produção mundial. O segundo e o terceiro maiores produtores de açúcar são a Índia e a China, com uma participação de 15\% e $10 \%$, respectivamente.

Cosan (2009) ainda afirma que

O Brasil é o produtor de açúcar com menores custos do mundo em função de seu clima favorável e dos desenvolvimentos tecnológicos, agrícolas e industriais. Tais desenvolvimentos resultam em ciclos de safra mais longos, maior produção de cana-de-açúcar processada e redução nas perdas industriais que resulta em uma maior produção de açúcar.

A produção de 2011 foi de 479,35 milhões de toneladas iniciada em abril até 15 de novembro, deste total $51,57 \%$ destinou-se à produção de etanol e $48,43 \%$ à produção de açúcar (UDOP, 2012).

Na região do Vale Paranapanema o clima e o solo são favoráveis para o cultivo da cana-de-açúcar, resultando em uma alta produção. Alguns cuidados são tomados após a realização do plantio e da primeira colheita, pois é necessário que se faça a manutenção da soqueira, ou seja, os tratos culturais (correção do solo, controle de pragas e doenças, etc.), pois o plantio da cana-de-açúcar é durável de 5 a 8 anos.

No processo industrial alguns resíduos (subprodutos) são liberados após o processo de transformação da cana em açúcar ou álcool, que são utilizados para aplicação no solo, trazendo benefícios e uma grande economia de recursos.

A cultura da cana-de-açúcar não é muito exigente em relação ao clima comparando-se a outras culturas como, por exemplo, a soja que necessita de períodos climáticos favoráveis para o seu desenvolvimento até o período de colheita. A soja é uma planta mais sensível, o clima deve ser muito favorável a ela, seja para o plantio, crescimento e colheita. Baixas ou altas temperaturas prejudicam o seu 
Análise dos custos de produção dos agentes biológicos para controle de diatraea saccharalis em cana-de-açúcar: Um estudo de caso em laboratório de produção massal

Paulo Arnaldo Olak, Joice Amarante

desenvolvimento. Acredita-se que o ideal para uma ótima produção sejam variações climáticas de $20^{\circ} \mathrm{C}$ e $30^{\circ} \mathrm{C}$, além de quantidade equilibrada de chuvas.

Alguns agricultores da região estão deixando de produzir a soja e passando a produzir a cana-de-açúcar, pois segundo eles quando a produção da soja é perfeita com uma ótima colheita destina-se, aproximadamente, $80 \%$ do total ganho aos custos, sendo assim este cultivo é de uma cultura de alto risco.

\subsection{Broca da Cana-de-açúcar}

A broca da cana-de-açúcar, diatraea saccharalis, é a principal praga da lavoura da cana, originária da América Central e do Sul. O primeiro relato de ocorrência dessa praga no Brasil foi em 1841 em canaviais de Santa Catarina (GAGLIUMI, 1973 apud SAZAKI, 2006).

Segundo Gallo (2002 apud SAZAKI, 2006), "o adulto da broca-da-cana é uma mariposa com cerca de $25 \mathrm{~mm}$ de envergadura" com coloração branco-amarelada e cabeça com manchas em tons marrom-escuro. De início sua alimentação é à base das folhas da planta, logo após penetram no colmo passando a se alimentar da própria planta.

Uma infestação da broca na lavoura da cana-de-açúcar torna a sua atividade inviável, sendo esta a praga mais conhecida no cultivo da cana. As lagartas causam prejuízos diretos por se instalarem dentro do colmo da planta, podendo levá-la a morte, pois se a cana for muito jovem começa a secar suas folhas e logo após a morte do broto, portanto, consequentemente a morte da cana.

As perdas na produção da cana-de-açúcar são calculadas por meio de índice de intensidade de infestação, através do qual é possível medir a perda da produtividade final da cana em relação função da broca.

Atualmente, a principal forma de controle utilizada é o controle biológico, ou seja, a liberação do parasitóide cotesia flavipes na lavoura da cana-de-açúcar, que além de proporcionar resultados positivos, não provoca desequilíbrio biológico. Também é disponibilizado no mercado o controle químico sendo também bastante 
Análise dos custos de produção dos agentes biológicos para controle de diatraea saccharalis em cana-de-açúcar: Um estudo de caso em laboratório de produção massal

Paulo Arnaldo Olak, Joice Amarante

utilizado, mas com resultados não muito positivos devido à dificuldade do produto químico atingir a lagarta que se encontra penetrada no colmo.

\subsection{Cotesia flavipes}

"Cotesia flavipes é uma vespa endoparasitóide introduzida no Brasil para controlar biologicamente o hospedeiro diatraea saccharalis, conhecida como a broca da cana-de-açúcar" (UEHARA, 2007). Trazida da Ásia ao país em 1974, se destaca em diversas regiões como importante inimigo natural.

Segundo Moutia e Courtois (1952) e Voterelli et al. (1999) apud Volpe (2009) "seu ciclo de vida é de aproximadamente 20 dias, sua reprodução é através das fêmeas que depositam ovos fertilizados dando origem a descendentes do sexo feminino e dos ovos não fertilizados originam-se os machos".

Facilmente se diferenciam os parasitóides entre macho e fêmea, pois os machos possuem antenas grandes e não ovopositam quando em contato com a lagarta, já as fêmeas possuem antenas menores e quando entram em contato com a lagarta elas ovopositam, ou seja, pousa sobre a lagarta curvando suas antenas na entrada do orifício aberto pela praga para assim inserir seu ovipositor, colocando em média 50 ovos em cada larva da praga. Em três dias nasce a larva do parasitóide, alimentando-se e se desenvolvendo dentro do corpo da praga, e em poucos dias ela morre surgindo assim as massas de casulos de onde eclodirão novas vespas. "As vespas adultas são pequenas de 3 a $4 \mathrm{~mm}$ de comprimento e vivem por, aproximadamente, 34 horas a $25^{\circ} \mathrm{C}$, se alimentadas" (SANTOS, 2009).

Para Parra (2000 apud VOLPE, 2009)

Os parasitoides produzidos em laboratório são os mais utilizados no controle de pragas, devido ao baixo custo, fácil manipulação e por se alimentarem da própria praga (em certa fase da vida), não sendo necessário o uso de uma dieta específica para eles. 
Análise dos custos de produção dos agentes biológicos para controle de diatraea saccharalis em cana-de-açúcar: Um estudo de caso em laboratório de produção massal

Paulo Arnaldo Olak, Joice Amarante

\subsubsection{Liberação da cotesia flavipes na lavoura}

Após a realização do levantamento no campo com a definição das áreas mais infestadas pela praga, ocorre a liberação da cotesia flavipes no campo nas primeiras horas do dia. Segundo Pinho et al. (2006 apud VOLPE, 2009),

O produto "vespinhas" é comercializado em copo plástico de $100 \mathrm{ml}$ com tampa, contendo 30 massas de pupas em seu interior, com cerca de 1500 parasitoides, ou seja, 50 parasitoides emergidos por massa. Esses copos são mantidos em temperatura de $27^{\circ} \mathrm{C}$ e umidade relativa do ar de $80 \%$ até a emergência dos parasitoides. A liberação pode ser realizada após 12 horas do início da emergência dos parasitoides, para que haja emergência quase total e cópula dos mesmos.

Para se realizar a liberação da cotesia flavipes no campo, conta-se 25 metros do início do talhão e coloca-se o copo aberto nas folhas da cana, contando mais 50 metros é colocado outro copo aberto, sendo esta medida baseada no perímetro de vôo da vespa, onde nos horários mais frescos do dia ela cobre mais de 25 metros.

Após 10 ou 15 dias da liberação da cotesia flavipes deve-se fazer uma avaliação da eficiência da liberação, portanto, é necessário que se retorne ao campo e colete algumas lagartas, mantendo-as em recipientes plásticos com a dieta para sua alimentação (a mesma utilizada no laboratório) por alguns dias para se confirmar o parasitismo, ou seja, para que as larvas se transformem em pupas com novas cotesia flavipes.

\subsubsection{Departamentalização e produção da cotesia flavipes}

Para produzir os inimigos naturais da broca da cana-de-açúcar em massa (Produção em Laboratório), segundo Santos (2009), "é necessário se ter um conhecimento avançado de entomologia, conhecer todas as características da praga e do agente entomopatogênico". Sendo necessário produzir primeiramente a própria praga. 
Análise dos custos de produção dos agentes biológicos para controle de diatraea saccharalis em cana-de-açúcar: Um estudo de caso em laboratório de produção massal

Paulo Arnaldo Olak, Joice Amarante

O processo de produção da cotesia flavipes é separado por departamentos e alguns cuidados devem ser tomados antes de se iniciar a produção, tais como: o uso de máscaras, a higienização das mãos com água, sabão e álcool para minimizar a possibilidade de contaminação dentro do laboratório e todos os materiais utilizados devem ser esterilizados após cada período de uso. A departamentalização compreende, segundo o Laboratório Biológico de produção de cotesia flavipes (2011):

Sala de dieta: onde é preparado o alimento da broca, ou seja, é uma ração balanceada, preparada à base de levedura, farelo de soja, germe de trigo, açúcar, vitaminas e anticontaminantes, sendo preparadas em dois processos diferentes, ou seja, uma para a dieta em tubos para formação das brocas e a outra em tabletes para realimentação da broca já inoculada. Identificamos ser o setor mais "caro" da produção, pois é o departamento que mais se utiliza de materiais.

Sala de postura: onde se mantém as câmaras com adultos para acasalamento e obtenção de postura. As câmaras são tubos de PVC de aproximadamente 6 polegadas de diâmetro e $20 \mathrm{~cm}$ de altura, revestidas com 2 folhas de papel sulfite onde as fêmeas efetuam as posturas, são colocadas 50 casais de mariposas de broca-da-cana em cada câmara (as fêmeas são maiores, com as asas anteriores geralmente pouco pigmentadas e abdome volumoso e os machos são menores, asas anteriores geralmente com pigmentação bem visível e abdome delgado), as câmaras são colocadas sobre uma mesa e tampadas, no centro é colocado um algodão umedecido com água para alimentação das mesmas. Para o acasalamento das mariposas a luz não poderá ficar acesa durante a noite, contudo no dia seguinte são retirados os papéis que revestem o interior da câmara, pois contém os ovos, colocamse novos papéis nas câmaras e para obtenção de novas posturas junta-se em cada câmara 100 casais de mariposas. No outro dia as mesmas serão eliminadas do processo.

Desinfecção dos ovos: Os papéis retirados das câmaras são então levados para desinfecção dos ovos, onde são utilizadas três bandejas, uma contendo água, outra formol e outra novamente água, deixando-se um minuto a folha dentro de cada 
Análise dos custos de produção dos agentes biológicos para controle de diatraea saccharalis em cana-de-açúcar: Um estudo de caso em laboratório de produção massal

Paulo Arnaldo Olak, Joice Amarante

bandeja. Após a desinfecção das folhas de papel, as mesmas são colocadas para secarem por um dia, sendo recolhidas e colocadas em saquinhos de papeis manteiga, após 5 dias as larvas já estão bem definidas e prestes a eclodir.

Inoculação dos ovos em tubos com dieta: Os ovos são de coloração amarela, após alguns dias este amarelo fica mais intenso e em seu interior é possível visualizar um ponto preto que indica ser dos olhos das lagartas. Os papéis contendo os ovos são cortados em pedaços deixando em média 40 ovos em cada pedaço, estes pedaços de papéis são colocados em tubos contendo a dieta, logo após, estes tubos são levados para uma sala com temperatura controlada por 15 dias (tempo para formação das lagartas). Nesta etapa do processo tem-se um responsável para visualizar todos os tubos com brocas, observando se tem algum ponto de fungo dentro dos tubos, caso tenha é retirado e dependendo as condições este tubo é eliminado do processo.

Sala de separação de alimento para broca inoculada: As brocas inoculadas são colocadas em placas de petri (latinhas transparentes) contendo os tabletes de dieta de realimentação. Nesta etapa do processo é colocado um tablete de dieta em cada latinha.

Sala de inoculação de brocas: Após 15 dias as lagartas estão prontas para serem inoculadas. As lagartas são despejadas sobre uma placa e cada larva é pega com a mão com muito cuidado para não feri-la ou matá-la, esta é colocada perto de uma vespa fêmea e com isso, a vespa sobe na lagarta ovopositando sobre a mesma. Só deve-se inocular uma vespa por lagarta. As mesmas são colocadas nas "latinhas" contendo dieta para sua realimentação, são colocadas 5 brocas inoculadas em cada latinha.

Sala das lagartas inoculadas: Estas ficam em "latinhas" com dieta de realimentação por mais 15 dias. Após a picada da Cotesia flavipes sobre a broca é depositado em média 50 ovos em seu interior, estes dão origem a larvinhas que se desenvolverão, especialmente dos tecidos de reserva da lagarta. Completado o período de alimentação, as pequenas larvas migram para fora do corpo da lagarta e 
Análise dos custos de produção dos agentes biológicos para controle de diatraea saccharalis em cana-de-açúcar: Um estudo de caso em laboratório de produção massal

Paulo Arnaldo Olak, Joice Amarante

formam casulos, dando continuidade a seu ciclo, a lagarta por sua vez, morre, sem conseguir completar seu ciclo.

Sala de revisão: 15 dias após a inoculação, faz-se a revisão, ou seja, retira-se as massas de Cotesia flavipes formadas (cada latinha contém 5 massas de cotesia), e estas são colocadas em copos plásticos (cada copo deve conter 30 massas). À medida que se aproxima a emergência dos adultos ( 3 a 4 dias), as massas vão se tornando escuras até eclodirem, obtendo-se então a Cotesia flavipes prontas para liberação no campo de cultivo da cana-de-açúcar.

Sala de revisão para formação de cotesia para o laboratório: O laboratório necessita de Cotesia para a inoculação da broca, portanto faz-se uma seleção das melhores massas de cotesia, onde são separadas 15 massinhas por lata, as mesmas ficam dois dias para "estourarem" e mais 8 horas para se acasalarem, a partir disso podem ir para o processo de inoculação da broca.

Lagartas não inoculadas: É o mesmo processo, mas desta vez a lagarta não é atacada pela Cotesia, são colocadas 7 brocas por lata e após 15 dias as lagartas ficam velhas e se transformam em crisálidas, as mesmas são levadas para sala de postura onde são colocadas em uma espécie de gaiola para se transformarem em borboletas, sendo assim o processo se torna um círculo continuando a produção de Cotesia flavipes.

Lavanderia: Todos os tubos de lagartas e as latinhas com as massas de Cotesia, depois de concluído seu processo no laboratório, são encaminhados para lavanderia, utiliza-se cloro para higienização dos mesmos.

\subsection{Custos do Controle de Pragas}

Existem duas formas de controle da praga $D$. saccharalis (broca da cana-deaçúcar): o controle biológico ou o controle químico. No controle químico são usados inseticidas de diferentes modos de ação assim como diferentes princípios ativos e no controle biológico utiliza-se do parasitóide larval cotesia flavipes, pois é um dos inimigos mais utilizados em cana-de-açúcar com eficiente controle em condições de 
Análise dos custos de produção dos agentes biológicos para controle de diatraea saccharalis em cana-de-açúcar: Um estudo de caso em laboratório de produção massal

Paulo Arnaldo Olak, Joice Amarante

campo (MENA, 2010). O autor explica que quando se escolher realizar o controle através do controle químico, para a eficiência de inseticidas, estes devem ser aplicados enquanto as lagartas são ainda jovens e antes das mesmas penetrarem no interior do colmo.

"O uso de C. flavipes para controle de D. saccharalis em cana é um dos maiores programas de controle biológico em todo o mundo, com base na extensão da área tratada" (VACARI; DE BORTOLI, 2010).

Estudos indicam que para cada 1\% de índice de infestação ocorrem perdas médias de 1,14\% na produção de cana, acrescidas de 0,42\% na produção de açúcar e 0,21\% na produção de álcool (ASSOCANA, 2012).

O custo total para manutenção da cultura da cana-de-açúcar por hectare é equivalente à $R \$ 893,23$ (oitocentos e noventa e três reais e vinte e três centavos), sendo deste total apenas $2 \%$ destinado ao controle da broca da cana-de-açúcar através do parasitóide larval cotesia flavipes. Considera-se um baixo custo em relação ao benefício que se obtém através de tal controle, pois um estudo realizado levantou que o índice de infestação de $11 \%$ foi reduzido para $2 \%$ nos últimos anos, devido ao controle biológico (ASSOCANA, 2012).

A liberação das vespas ocorre dependendo da intensidade populacional da broca. A União dos Produtores de Bioenergia (UDOP) recomenda a liberação de 6.000 vespas por hectare (4 copos por hectare) quando a intensidade de infestação chegar a $3 \%$, ou em áreas com grande infestação recomenda-se a liberação de 8 copos com 15 massas (o número de vespas é o mesmo, porém a liberação é mais homogênea e mais eficiente) (EBAH, 2012).

\section{MATERIAIS E MÉTODOS}

Esta pesquisa foi realizada em um Laboratório de Produção Massal de cotesia flavipes, localizado no Vale do Paranapanema, Estado de São Paulo, Brasil, cujo objetivo é a formação e análise do custo de produção da cotesia flavipes, Para tal 
Análise dos custos de produção dos agentes biológicos para controle de diatraea saccharalis em cana-de-açúcar: Um estudo de caso em laboratório de produção massal

Paulo Arnaldo Olak, Joice Amarante

análise foi necessário acompanhar o processo produtivo para se obter o custo total de produção, analisando-se, primeiramente, um mês de produção com capacidade total, para assim determinar os resultados. No seu desenvolvimento foi utilizado o custeio baseado em atividades (ABC).

A opção pelo método de custeio $A B C$ levou em consideração o exposto por Martins (2008, p.295), onde o autor menciona:

O uso do $A B C$ é extraordinário em termos de identificar o custo das atividades e dos processos e de permitir uma visão muito mais adequada para a análise da relação custo/benefício de cada uma dessas atividades e desses processos. Permite o levantamento do quanto se gasta em determinadas atividades, tarefas e processos onde não se agrega valor ao produto [...].

Trata-se de um tipo de pesquisa que privilegia um caso em particular, objetivando colaborar na tomada de decisões sobre o problema estudado, indicando possíveis modificações.

Quanto ao objetivo a pesquisa é classificada como exploratória, uma vez que se trata de uma área com muito pouco conhecimento acumulado, objetivando-se, assim, obter maior familiaridade com todo o contexto. A mesma foi desenvolvida dentro do próprio laboratório, tendo-se acompanhado todo o processo.

\section{APRESENTAÇÃO E ANÁLISE DOS DADOS}

\subsection{Descrição do Processo Produtivo}

Para o levantamento dos custos de produção de cotesia flavipes foram considerados apenas os custos operacionais. Justifica-se tal utilização, pois o laboratório já se encontra em operação. Assim, o custo operacional foi obtido através de informações e análises realizadas no laboratório no mês de fevereiro de 2012. 
Análise dos custos de produção dos agentes biológicos para controle de diatraea saccharalis em cana-de-açúcar: Um estudo de caso em laboratório de produção massal

Paulo Arnaldo Olak, Joice Amarante

A capacidade de produção para o mês analisado foi de 80.035 copos, sendo que cada copo contém 30 massas de pupas, ou seja, a produção total foi de 2.401 .050 massas de pupas.

O processo produtivo conta com vários departamentos. Visando o detalhamento da análise, descrevem-se, a seguir, cada parte do processo:

a) Formação de Matrizes: As matrizes são obtidas através de "borboletas" (macho e fêmea) colocadas em tubos com alimentação própria, ou seja, um algodão umedecido com água, por 24 horas, permanecendo em sala escura para acasalamento, estes tubos são revestidos com folha de papel sulfite onde as mesmas colocam seus ovos. Esses ovos são encaminhados para a desinfecção a base de água e formol.

b) Desinfecção dos ovos: Os ovos são recolhidos da sala de posturas e encaminhados para desinfecção. As folhas de papel que contém os ovos são desinfetadas primeiramente passando por bandejas com água, em seguida formol e novamente água, permanecendo 1 minuto em cada bandeja. Depois de realizado este processo as mesmas são colocadas para secar por 24 horas, após a secagem são retiradas e colocadas em saquinhos de papel manteiga por mais 5 dias até os ovos estarem bem definidos e prestes a eclodir, sendo possível ver um ponto preto nos ovos indicando ser os olhos da lagarta.

c) Dieta: este departamento utiliza-se de vários materiais para formação da alimentação da broca da cana-de-açúcar. Considera-se uma ração balanceada, preparada à base de levedura, farelo de soja, germe de trigo, açúcar, vitaminas e anticontaminantes, esta alimentação é preparada por três processos diferentes, ou seja, a dieta para a broca inoculada, outra para a broca não inoculada e outra para a formação da broca em tubos. O processo consiste na medida certa de cada ingrediente e água, levando tudo ao liquidificador industrial para mistura; após este processo o alimento é distribuído de acordo com a sua utilização. A dieta para formação da broca em tubos é uma alimentação "mole" distribuída em tubos, já a dieta para realimentação da broca (broca inoculada e não inoculada) é colocada em formas 
Análise dos custos de produção dos agentes biológicos para controle de diatraea saccharalis em cana-de-açúcar: Um estudo de caso em laboratório de produção massal

Paulo Arnaldo Olak, Joice Amarante

e após o seu endurecimento é cortada em pequenos quadradinhos, e para sua conservação são mantidas em salas refrigeradas até o momento da utilização.

d) Sala de separação de alimento da broca inoculada: esta etapa do processo exige eficiência e prática, pois não é possível realizar a inoculação da broca sem o alimento dentro das latinhas, portanto, o alimento é preparado na sala de dieta, cortado em pedaços que são colocados dentro das placas de petri para realimentação da broca.

e) Inoculação dos ovos em tubo com dieta: Os tubos já foram preparados no departamento de dieta e os ovos desinfetados e secos, sendo assim estas folhas, que continham os ovos, são cortadas em pequenos pedaços respeitando que cada tubo receba em média 40 ovos. Estes pedacinhos de papel contendo os ovos são colocados dentro do tubo com a dieta e tampados. Este departamento tem por responsabilidade a formação das brocas em tubos, onde as mesmas ficam acondicionadas por 15 dias até obterem condições para a inoculação, entretanto ainda é necessário que um colaborador acompanhe este período de crescimento para que não ocorra nenhum caso de fungo dentro dos tubos podendo prejudicar o laboratório por completo.

f) Inoculação das brocas: este departamento utiliza-se das lagartas em tubo que após 15 dias atingiram o tamanho necessário para a inoculação e também a dieta para realimentação da broca já separada em placas de petri. Portanto, o colaborador abre este tubo, retira as brocas e com a picada da cotesia flavipes é realizada a inoculação das mesmas, a partir disso colocam-se 5 brocas inoculadas em cada latinha, juntamente com a realimentação, levando-as para uma outra sala por mais 15 dias.

g) Lagartas não inoculadas: este departamento utiliza-se das mesmas lagartas que com 15 dias nos tubos estão prontas para utilização. A alimentação é um pouco diferente da utilizada para a broca inoculada, ou seja, alguns ingredientes são diferentes, mas o processo é o mesmo, entretanto desta vez não é utilizada a cotesia flavipes para inoculação, pois as lagartas não serão inoculadas apenas serão 
Análise dos custos de produção dos agentes biológicos para controle de diatraea saccharalis em cana-de-açúcar: Um estudo de caso em laboratório de produção massal

Paulo Arnaldo Olak, Joice Amarante

separadas 7 lagartas da broca e colocadas nas latinhas juntamente com a realimentação, onde as mesmas permanecerão por 15 dias; logo após serão encaminhadas para o departamento de posturas reiniciando o processo de produção de cotesia flavipes.

h) Revisão: Este departamento é o fechamento do processo de produção da cotesia flavipes, pois após as lagartas serem inoculadas elas ficam por 15 dias dentro das latinhas até se transformarem em massinhas, cada massa de pupa contém em média 50 cotesia flavipes, portanto, as mesmas são separadas retirando todo o excesso de realimentação da broca. Conta-se 30 massinhas e as coloca em copos descartáveis prontos para a comercialização.

i) Revisão para formação de cotesia para o laboratório: Esta etapa do processo exige muita atenção, pois antes do departamento de revisão iniciar suas atividades é necessário que se retirem as melhores massinhas (latinhas) para continuidade do laboratório. As mesmas são selecionadas dentre todas da produção do dia, levadas para o departamento correspondente, separadas da realimentação e colocadas em latinhas novamente até a sua eclosão para utilização no processo de inoculação das lagartas da broca. Para conservá-las após estarem limpas são colocadas em latinhas e mantidas em refrigeração até o dia do uso, retiradas da refrigeração 8 horas antes da utilização, estando prontas para o processo de inoculação.

j) Lavanderia: Todos os tubos com restos da dieta para formação da broca, ou seja, tubos que continham lagartas utilizadas para a inoculação e as latinhas com a realimentação de onde foram retiradas as massinhas de cotesia são encaminhados para a lavanderia, são lavados com água e cloro, e após o enxágue as latinhas são secadas ao sol e os tubos são encaminhados para esterilização em forno próprio. Com isso, tanto os tubos quanto as placas de petri (latinhas) estão prontas para retornarem ao processo de produção de cotesia flavipes.

Para melhor entendimento do processo produtivo de cotesia flavipes, apresenta-se o fluxograma a seguir (Figura 1). 
Análise dos custos de produção dos agentes biológicos para controle de diatraea saccharalis em cana-de-açúcar: Um estudo de caso em laboratório de produção massal

Paulo Arnaldo Olak, Joice Amarante

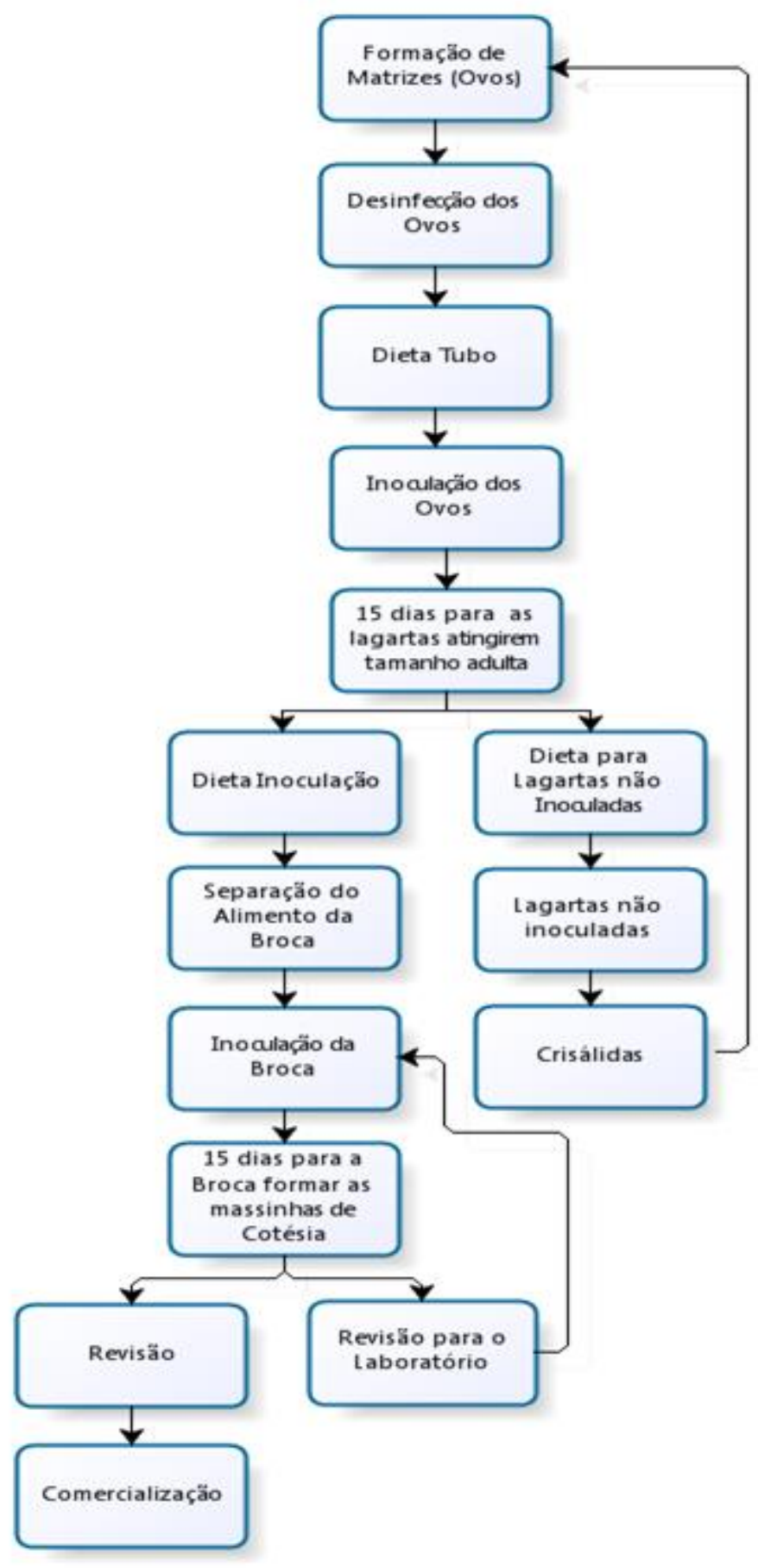

Figura 1 - Fluxograma do Processo de Produção de Cotesia flavipes 
Análise dos custos de produção dos agentes biológicos para controle de diatraea saccharalis em cana-de-açúcar: Um estudo de caso em laboratório de produção massal

Paulo Arnaldo Olak, Joice Amarante

\subsection{Custos de Produção de Cotesia flavipes}

Muitos são os custos envolvidos no processo de produção de cotesia flavipes, sendo que cerca de $70 \%$ dos custos está associado com o trabalho, ou seja, apenas mão-de-obra (VACARI, 2010).

Nem todos os departamentos descritos anteriormente utilizam materiais, pois acatam os materiais dos procedimentos anteriores, e utilizando-se apenas de mão-deobra finalizam mais uma etapa do processo.

O custo de produção subdivide-se em departamentos, ou seja, cada departamento absorve uma parcela de custos. Para este estudo foram levantados os custos do mês de fevereiro de 2012 com a capacidade total de produção. Entretanto, considerando o objetivo do estudo, apenas os custos dos materiais e mão-de-obra direta da produção estão sendo considerados, conforme Tabela 1, a seguir.

Tabela 1: Custos de Produção por Departamento

\begin{tabular}{|c|c|c|c|}
\hline Departamento & $\begin{array}{c}\text { Matéria- } \\
\text { prima/Materiais } \\
(\mathbf{R} \mathbf{\text { ) }}\end{array}$ & $\begin{array}{c}\text { Mão-de-obra } \\
\mathbf{( R \mathbf { \$ } )}\end{array}$ & Total (R\$) \\
\hline Formação de Matrizes & 396,65 & $2.549,55$ & $2.946,20$ \\
\hline Desinfecção dos ovos & 14,75 & $1.699,70$ & $1.714,45$ \\
\hline Dieta (alimentação) & $43.698,50$ & $2.549,55$ & $46.248,05$ \\
\hline Separação do alimento da broca & 11,20 & $6.798,80$ & $6.810,00$ \\
\hline Inoculação ovos e lagartas crisálidas & 51,80 & $1.699,70$ & $1.751,50$ \\
\hline Inoculação da broca & 346,60 & $63.738,75$ & $64.085,35$ \\
\hline Revisão & $4.072,00$ & $20.396,40$ & $24.468,40$ \\
\hline Revisão para laboratório & 9,55 & $1.699,70$ & $1.709,25$ \\
\hline Lavanderia & $2.003,10$ & $3.399,40$ & $5.402,50$ \\
\hline Total & $50.604,15$ & $104.531,55$ & $155.135,70$ \\
\hline
\end{tabular}

Fonte: Dados da pesquisa.

O custo total de produção de cotesia flavipes no mês de fevereiro de 2012 foi de $R \$ 155.135,70$, com uma produção de 80.035 copos, lembrando que em cada copo contém 30 massas de pupas. Do custo total da produção, $\mathrm{R} \$ 50.604,15$ são de materiais e $\mathrm{R} \$ 104.531,55$ de mão-de-obra, ou seja, $67 \%$ do custo total da produção são direcionados aos serviços (mão-de-obra) e 33\% é composto por materiais na realização dos processos. Cada copo de cotesia flavipes no processo de produção 
Análise dos custos de produção dos agentes biológicos para controle de diatraea saccharalis em cana-de-açúcar: Um estudo de caso em laboratório de produção massal

Paulo Arnaldo Olak, Joice Amarante

custou para a empresa $R \$ 1,94$, e como os mesmos contém 30 massas de pupas, cada massa teve um custo de $\mathrm{R} \$ 0,06$.

O departamento com maior consumo de matéria-prima foi o da Dieta, responsável por $86 \%$ do custo total de materiais. Nessa etapa do processo o departamento de Dieta concentra toda a produção do laboratório, pois faltando ou não sendo de boa qualidade algum ingrediente do preparo da alimentação da broca, toda a produção é comprometida.

Considerando os serviços (mão-de-obra), maior recurso utilizado dentro do laboratório, dentre todos os setores o de maior volume é o da Inoculação da broca, responsável por $61 \%$ do custo total de mão-de-obra, pois é uma etapa do processo delicada, onde o colaborador pega a lagarta com as mãos levando-a até a cotesia flavipes para o parasitismo, em seguida coloca 5 lagartas nas latinhas juntamente com a realimentação.

O departamento de Revisão é o segundo com maior consumo de mão-de-obra, ou seja, $20 \%$ do custo total de serviços. Esta etapa já é mais rápida, pois o colaborador com uma pinça separa as massinhas de cotesia dos restos de realimentação, juntando 30 massinhas para colocar nos copos descartáveis com tampa prontos para comercialização.

Entre os departamentos com menores custos encontram-se o da desinfecção dos ovos, inoculação dos ovos e lagartas e o da revisão para o laboratório, cada uma destas etapas consome apenas $1 \%$ do custo total de produção do laboratório, pois são departamentos com funções ágeis, utilizando-se de pouca mão-de-obra, permanecendo assim com baixos custos. O custo total por departamento pode ser observado no Gráfico 1. 
Análise dos custos de produção dos agentes biológicos para controle de diatraea saccharalis em cana-de-açúcar: Um estudo de caso em laboratório de produção massal

Paulo Arnaldo Olak, Joice Amarante

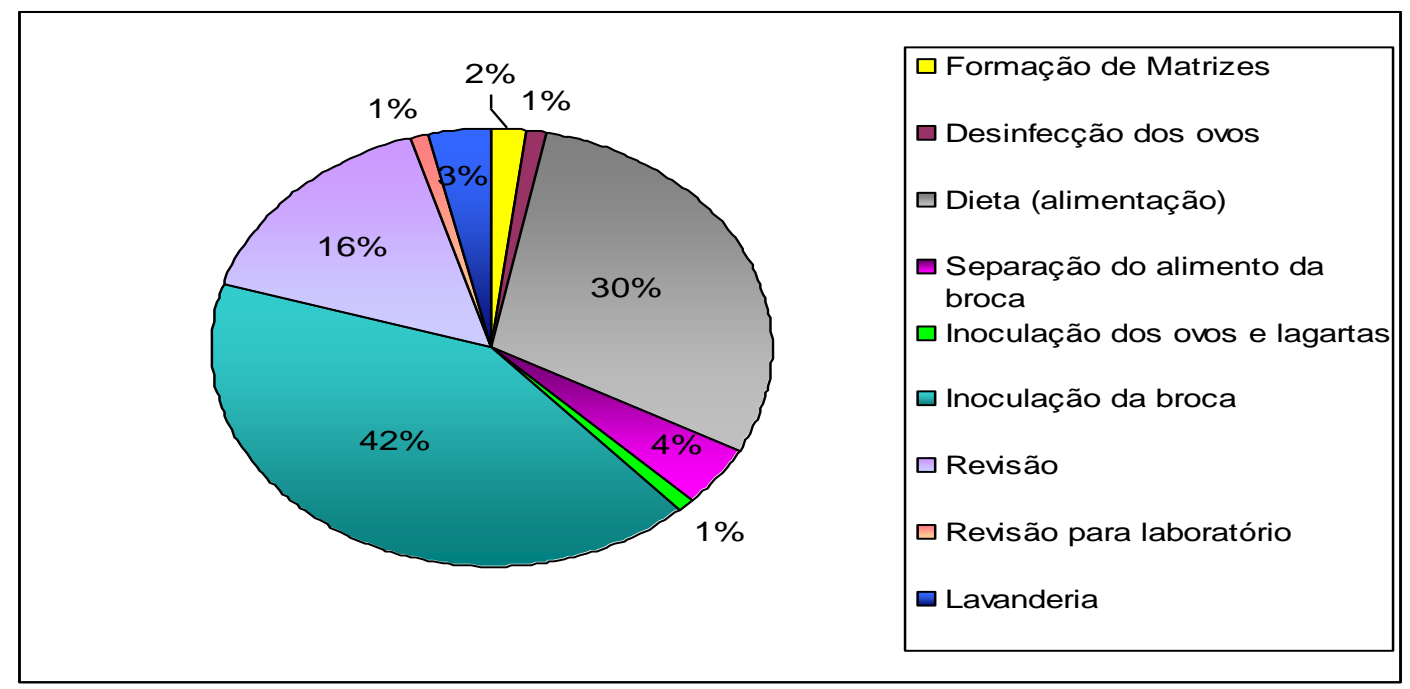

Gráfico 1: Custo Total por Departamento Fonte: Dados da pesquisa.

\subsection{Formas de mensuração e Reconhecimento dos Custos por Departamento}

A mensuração contábil do processo de produção está voltada à totalidade da produção mensal de cotesia flavipes, todos os custos de serviços e materiais foram designados dentro do mesmo mês de acordo com a produção dos agentes biológicos. Os departamentos utilizam-se de diferentes materiais, detalhados a seguir para melhor análise:

Formação de matrizes: este departamento consome folhas de papel sulfite para coleta dos ovos, algodão como fonte de alimento para borboletas (umedecidos a água) e EPI (equipamento de proteção individual).

Desinfecção dos ovos: consome apenas do formol para desinfecção dos ovos.

Dieta (alimentação): este departamento consome vários ingredientes para formação da alimentação da broca da cana-de-açúcar, esta alimentação é preparada por 3 receitas "diferentes", sendo uma para o tubo (dieta "mole") para formação das lagartas, outra para as brocas inoculadas e a outra para a broca não inoculada para manutenção do laboratório (crisálidas), também utiliza-se de equipamento de proteção individual. 
Análise dos custos de produção dos agentes biológicos para controle de diatraea saccharalis em cana-de-açúcar: Um estudo de caso em laboratório de produção massal

Paulo Arnaldo Olak, Joice Amarante

Separação do alimento da broca: consome apenas os equipamentos de proteção individual.

Inoculação dos ovos e lagartas para crisálidas: na inoculação dos ovos onde são colocados os pedaços de papeis contendo os ovos nos tubos com a dieta consomem-se pequenos pedaços de papel antes de colocar a tampa, pois esta tampa possui uma telinha no centro, evitando assim o material ficar exposto ao ar, utiliza-se também de equipamentos de proteção individual.

Inoculação da broca: consome apenas os equipamentos de proteção individual e produtos de higiene para desinfecção do local, evitando infecções aos agentes biológicos.

Revisão: é a etapa final do processo, sendo assim são necessários copos descartáveis com tampa para embalagem do produto, equipamentos de proteção individual e produtos para desinfecção do local de trabalho.

Revisão para o laboratório: nesta etapa as massinhas de cotesia flavipes são utilizadas para a manutenção do laboratório, portanto, não são colocadas em copos descartáveis, as mesmas são mantidas nas latinhas. Sendo assim, este departamento consome apenas de equipamentos de proteção individual.

Lavanderia: é a base para lavagem de todos os tubos e latinhas é apenas o cloro, consumindo também dos equipamentos de proteção individual.

O reconhecimento contábil do processo de produção de cotesia flavipes foi efetuado de acordo com a natureza dos serviços, ou seja, para determinação do custo de produção foram levantados os registros contábeis em contas específicas formando assim o custo de cada departamento e no final o custo total da produção do parasitóide cotesia flavipes. Os registros contábeis realizados em 29 de fevereiro de 2012, após encerramento da produção mensal do parasitóide cotesia flavipes, estão representados nos quadros a seguir. 
Análise dos custos de produção dos agentes biológicos para controle de diatraea saccharalis em cana-de-açúcar: Um estudo de caso em laboratório de produção massal

Paulo Arnaldo Olak, Joice Amarante

\begin{tabular}{|c|c|c|c|}
\hline Classificação & Débito & Crédito & Histórico \\
\hline Custo formação de matrizes & 396,65 & & Materiais para produção \\
\hline Estoque de materiais & & 396,65 & Materiais para produção \\
\hline Custo formação de matrizes & $2.549,55$ & & Serviços \\
\hline Salários a pagar & & $2.549,55$ & Serviços \\
\hline
\end{tabular}

Quadro 2: Formação de Matrizes

\begin{tabular}{|c|c|c|c|}
\hline Classificação & Débito & Crédito & Histórico \\
\hline Custo desinfecção dos ovos & 14,75 & & Materiais para produção \\
\hline Estoque de materiais & & 14,75 & Materiais para produção \\
\hline Custo desinfecção dos ovos & $1.699,70$ & & Serviços \\
\hline Salários a pagar & & $1.699,70$ & Serviços \\
\hline
\end{tabular}

Quadro 3: Desinfecção dos ovos

\begin{tabular}{|c|c|c|c|}
\hline Classificação & Débito & Crédito & Histórico \\
\hline Custo dieta (alimentação) & $43.698,50$ & & Materiais para produção \\
\hline Estoque de materiais & & $43.698,50$ & Materiais para produção \\
\hline Custo dieta (alimentação) & $2.549,55$ & & Serviços \\
\hline Salários a pagar & & $2.549,55$ & Serviços \\
\hline
\end{tabular}

Quadro 4: Dieta (alimentação)

\begin{tabular}{|c|c|c|c|}
\hline Classificação & Débito & Crédito & Histórico \\
\hline Custo separação alimento & 11,20 & & Materiais para produção \\
\hline Estoque de materiais & & 11,20 & Materiais para produção \\
\hline Custo separação alimento & $6.798,80$ & & Serviços \\
\hline Salários a pagar & & $6.798,80$ & Serviços \\
\hline
\end{tabular}

Quadro 5: Separação do alimento da broca 
Análise dos custos de produção dos agentes biológicos para controle de diatraea saccharalis em cana-de-açúcar: Um estudo de caso em laboratório de produção massal

Paulo Arnaldo Olak, Joice Amarante

\begin{tabular}{|c|c|c|c|}
\hline Classificação & Débito & Crédito & Histórico \\
\hline Custo inoculação ovos e crisálidas & 51,80 & & Materiais para produção \\
\hline Estoque de materiais & & 51,80 & Materiais para produção \\
\hline Custo inoculação ovos e crisálidas & $1.699,70$ & & Serviços \\
\hline Salários a pagar & & $1.699,70$ & Serviços \\
\hline
\end{tabular}

Quadro 6: Inoculação dos ovos e lagartas crisálidas

\begin{tabular}{|c|c|c|c|}
\hline Classificação & Débito & Crédito & Histórico \\
\hline Custo inoculação broca & 346,60 & & Materiais para produção \\
\hline Estoque de materiais & & 346,60 & Materiais para produção \\
\hline Custo inoculação broca & $63.738,75$ & & Serviços \\
\hline Salários a pagar & & $63.738,75$ & Serviços \\
\hline
\end{tabular}

Quadro 7: Inoculação da broca

\begin{tabular}{|c|c|c|c|}
\hline Classificação & Débito & Crédito & Histórico \\
\hline Custo Revisão & $4.072,00$ & & Materiais para produção \\
\hline Estoque de materiais & & $4.072,00$ & Materiais para produção \\
\hline Custo Revisão & $20.396,40$ & & Serviços \\
\hline Salários a pagar & & $20.396,40$ & Serviços \\
\hline
\end{tabular}

Quadro 8: Revisão

\begin{tabular}{|c|c|c|c|}
\hline Classificação & Débito & Crédito & Histórico \\
\hline Custo Revisão laboratório & 9,55 & & Materiais para produção \\
\hline Estoque de materiais & & 9,55 & Materiais para produção \\
\hline Custo Revisão laboratório & $1.699,70$ & & Serviços \\
\hline Salários a pagar & & $1.699,70$ & Serviços \\
\hline
\end{tabular}

Quadro 9: Revisão para o Laboratório 
Análise dos custos de produção dos agentes biológicos para controle de diatraea saccharalis em cana-de-açúcar: Um estudo de caso em laboratório de produção massal

Paulo Arnaldo Olak, Joice Amarante

\begin{tabular}{|c|c|c|c|}
\hline Classificação & Débito & Crédito & Histórico \\
\hline Custo Lavanderia & $2.003,10$ & & Materiais para produção \\
\hline Estoque de materiais & & $2.003,10$ & Materiais para produção \\
\hline Custo Lavanderia & $3.399,40$ & & Serviços \\
\hline Salários a pagar & & $3.399,40$ & Serviços \\
\hline
\end{tabular}

Quadro 10: Lavanderia

Todos os custos foram alocados em contas contábeis específicas. A próxima etapa do desenvolvimento do estudo é a alocação dos custos de cada departamento em uma única conta específica, totalizando o custo de produção do mês, de acordo com o levantamento apresentado anteriormente.

\begin{tabular}{|c|c|c|}
\hline Classificação & Débito & Crédito \\
\hline Custo Total de Produção & $155.135,70$ & \\
\hline Custo Formação de matrizes & & $2.946,20$ \\
\hline Custo Desinfecção dos ovos & & $1.714,45$ \\
\hline Custo Dieta (alimentação) & & $46.248,05$ \\
\hline Custo Separação alimento & & $6.810,00$ \\
\hline Custo Inoculação ovos e crisálidas & & $1.751,50$ \\
\hline Custo Inoculação broca & & $64.085,35$ \\
\hline Custo Revisão & & $24.468,40$ \\
\hline Custo Revisão laboratório & & $1.709,25$ \\
\hline Custo Lavanderia & & $5.402,50$ \\
\hline
\end{tabular}

Quadro 11: Transferência de saldo evidenciando o custo total de produção

O saldo da conta Custo Total de Produção do mês será transferido para Estoque de Produtos Acabados disponibilizado para comercialização, sendo que o mesmo terá como valor histórico o custo de cada unidade produzida. 
Análise dos custos de produção dos agentes biológicos para controle de diatraea saccharalis em cana-de-açúcar: Um estudo de caso em laboratório de produção massal

Paulo Arnaldo Olak, Joice Amarante

\section{CONSIDERAÇÕES FINAIS}

Este estudo teve como objetivo identificar e analisar os custos de produção de cotesia flavipes mediante a utilização do método de custeio $A B C$. Cada etapa do processo foi estudada e descrita de acordo com suas técnicas dentro dos processos, os materiais e mão-de-obra foram alocados de acordo com a demanda de produção, direcionando cada custo para o departamento responsável pelo seu consumo.

O custo de produção de cotesia flavipes no mês de fevereiro de 2012, período de estudo, foi de $R \$ 1,94$ o copo, sendo que cada copo conta com 30 massas de pupas, ou seja, cada massa custou para a empresa produzi-la $\mathrm{R} \$ 0,06$.

O estudo realizado de apuração dos custos de produção de cotesia flavipes contribuiu para melhorar o desempenho dos controles dentro da empresa, pois várias sugestões foram propostas e parte delas aplicadas conforme a necessidade dos levantamentos, entendendo-se que o laboratório deve se beneficiar de tais informações para melhor desenvolvimento.

O método de custeio $A B C$ aplicado como fonte de estudo para o levantamento do custo de produção de cotesia flavipes, permite que os gerentes responsáveis analisem cada departamento da empresa, possibilitando visualizar os custos de cada área relacionando os períodos, pois a produção de cotesia flavipes também sofre períodos sazonais, conforme o aumento ou diminuição do ataque da broca em canade-açúcar.

\section{REFERÊNCIAS}

ANDRADE, José Henrique de. (2007). Planejamento e controle da produção na pequena empresa: estudo de caso de fatores intervenientes no desempenho de um empreendimento metalúrgico da cidade de São Carlos-SP. (Dissertação de mestrado). Escola de Engenharia de São Carlos da Universidade de São Paulo, 2007. Disponível em: $\quad$ http://www.teses.usp.br/teses/disponiveis/18/18140/tde-29112007-071559/ptbr.php>. Acesso em: 25/fev/2012. 
Análise dos custos de produção dos agentes biológicos para controle de diatraea saccharalis em cana-de-açúcar: Um estudo de caso em laboratório de produção massal

Paulo Arnaldo Olak, Joice Amarante

ASSOCIAÇÃO Rural dos Fornecedores e Plantadores de Cana da Média Sorocabana (ASSOCANA). Site Institucional. Disponível em: <http://www.assocana.com.br/. Acesso em: 25/fev/2012.

BEUREN, Ilse Maria. (1993). Conceituação e Contabilização do Custo de Oportunidade. Caderno de Estudos da Fipecafi. FEA-USP: São Paulo. Disponível em: $<$ http://www.eac.fea.usp.br/cadernos/completos/cad02/custoop.pdf>. Acesso em: 20/fev/2012.

BONATO, Rodrigo Giacomini. (2004). Qualidade operacional da fenação: análise do processo de produção, 2004. (Dissertação de mestrado). Escola Superior de Agricultura "Luiz de Queiroz", Piracicaba. Disponível em <http://www.teses.usp.br/teses/disponiveis/11/11148/tde-19112004-133218/pt-br.php>. Acesso em: 30/jan/2012.

BOTELHO, Ernani Mendes. (2006). Custeio baseado em atividades - ABC: Uma aplicação em uma organização hospitalar universitária. (Tese de Doutorado). Faculdade de Economia, Administração e Contabilidade da Universidade de São Paulo, São Paulo. Disponível em: <http://www.teses.usp.br/teses/disponiveis/12/12139/tde-10042008-102523/pt-br.php>. Acesso em: 22/jan/2012.

CATELLI, Armando (coordenador). (2009). Controladoria: uma abordagem da gestão econômica - GECON. (2. ed.). 7. reimpr. - São Paulo: Atlas.

CENTRO de Tecnologia Canavieira. Site oficial. <Disponível em: www.ctcanavieira.com.br>. Acesso em: 18/jan/2012.

COSAN. Site oficial. Disponível em: <www.cosan.com.br>. Acesso em: 20/jan/2012.

CREPALDI, Silvio Aparecido. (2008). Contabilidade Gerencial: teoria e prática. (4. 142 ed.). São Paulo: Atlas.

EBAH. Site institucional. Disponível em: $<$ http://www.ebah.com.br/content/ABAAABkpsAJ/broca-cana-acucar>. Acesso em: 08/fev/2012.

FIGUEIREDO, Sandra; CAGGIANO, Paulo César. (2008). Controladoria: teoria e prática. (4. 142 ed.). São Paulo: Atlas.

GERREIRO, Reinaldo. (2006). Gestão do Lucro. São Paulo: Atlas.

JIAMBALVO, James. (2009). Contabilidade Gerencial. (3. 142 ed.). Rio de Janeiro: LTC. 
Análise dos custos de produção dos agentes biológicos para controle de diatraea saccharalis em cana-de-açúcar: Um estudo de caso em laboratório de produção massal

Paulo Arnaldo Olak, Joice Amarante

LABORATÓRIO Biológico. Disponível em: <http://www.jallesmachado.com.br>. Acesso em: 03/mai/2011.

LEONE, George Sebastião Guerra. (2009). Curso de Contabilidade de Custos. (3. 143 ed.). São Paulo: Atlas.

LOPES, Carolina Schultz. (2008). Regulação do desenvolvimento e resposta imune de lagartas de Diatraea saccharalis (Fabricius) (143epidóptera: Cambridae) por Cotesia flavipes (Cameron) (Hymenoptera: Braconidae). (Dissertação de Mestrado). Escola Superior de Agricultura Luiz de Queiroz USP, São Paulo, 2008. Disponível em: <http://www.teses.usp.br/teses/disponiveis/11/11146/tde-16092008-161549/pt-br.php>. Acesso em: 20/abr/2011.

MARTINS, Eliseu. (2008). Contabilidade de Custos. (9. 143 ed.). 8. reimpr. - São Paulo: Atlas.

MATOS, Roselane Biangaman de. (2009). Planejamento da qualidade para o processo de produção de mudas clonais de eucalipto. (Tese de Doutorado). Escola Superior de Agricultura "Luiz de Queiroz", Piracicaba. Disponível em: <http://www.teses.usp.br/teses/disponiveis/11/11150/tde-25022010-160151/pt-br.php>. Acesso em: 31/jan/2012.

MEGLIORINI, Evandir. (2007). Custos: análise e gestão. (2. 143 ed.). São Paulo: Pearson Prentice Hall.

MENA, Edgar Francisco Gaona. (2010). Toxidade de inseticidas a Diatraea saccharalis (Fabr., 1794) (Lepidóptera: Crambidae) e Cotesia flavipes (Cameron, 1891) (Hymenoptera: Braconidae). (Dissertação de Mestrado). Universidade de São Paulo Escola Superior de Agricultura "Luiz de Queiroz", Piracicaba, 2010. Disponível em: $<143$ ep.teses.usp.br/teses/disponiveis/11/11146/tde.../Edgar_Mena.pdf>. Acesso em: 08/fev/2012.

NAKAGAWA, Masayuki. (1991). Gestão estratégica de custos: conceitos, sistemas e implementação. São Paulo: Atlas.

Paulo: Atlas.

(1993). Introdução à Controladoria: conceitos, sistemas, implementação. São

PADOVEZE, Clovis Luiz. (2009). Contabilidade gerencial: um enfoque em sistema de informação contábil. São Paulo: Atlas.

SALVADOR, Gabriela. (2010). Regulação da atividade do tecido adiposo de Diatraea saccharalis (Fabricius) (143epidóptera: Cambridae) parasitada por Cotesia flavipes 
Análise dos custos de produção dos agentes biológicos para controle de diatraea saccharalis em cana-de-açúcar: Um estudo de caso em laboratório de produção massal

Paulo Arnaldo Olak, Joice Amarante

(Cameron) (Hymenoptera: Braconidae). (Dissertação de Mestrado). Escola Superior de Agricultura Luiz de Queiroz USP, São Paulo. Disponível em: <http://www.teses.usp.br/teses/disponiveis/11/11146/tde-19042010-151948/pt-br.php>. Acesso em: 05/abr/2011.

SANTOS, Douglas Martins. (2009). Produção em massa de agentes biológicos para controle de Diatraea saccharalis em cana-de-açúcar, 2009. (Monografia). Faculdade de Ciências Exatas e da Terra, Dourados. Disponível em: http://www.webartigos.com/articles/27534/1/Producao-Massal-de-CotesiaFlavipes/pagina1.html>. Acesso em: 05/abr/2011.

SAZAKI, Catia Sumie Shimatai. (2006). Esterilização química da broca da cana-deaçúcar Diatraea saccharalis (Fabricius, 1794) (144epidóptera: Crambidae) através de isca com melaço e inseticidas do grupo dos reguladores de crescimento de insetos, 2006. Dissertação de Mestrado - Universidade de São Paulo Escola Superior de Agricultura "Luiz de Queiroz", Piracicaba. Disponível em: <http://www.teses.usp.br/teses/disponiveis/11/11146/tde-22112006-133733/fr.php>. Acesso em: 08/abr/2011.

TEIXEIRA, Flávio Luiz dos Santos. Custos do Controle de Pragas na cana-de-açúcar. Assis/SP, Assocana - Associação Rural dos Fornecedores e Plantadores de Cana da Média Sorocabana. 13/fev/2012. www.assocana.com.br. Entrevista a Joice Amarante.

UEHARA, Márcia Terumi. (2005). Estratégias de parasitismo da vespa parasitóide Cotesia flavipes, Cameron, 1891 (Hymenoptera: Braconidae). (Tese de Doutorado). Faculdade de Filosofia, Ciências e Letras de Ribeirão Preto, Ribeirão Preto, 2005. Disponível em:<http://www.teses.usp.br/teses/disponiveis/59/59131/tde-29082007154313/pt-br.php>. Acesso em: 14/abr/2011.

UNIÃO da Indústria de Cana-de-Açucar (UNICA). Disponível em: <http://www.unica.com.br/noticia/33684208920337715081/moagem-de-cana-naregiao-centro-sul-atinge-479-por-cento2C35-milhoes-de-toneladas/>. Acesso em: 07/mar/2012.

UNIÃO dos Produtores de Bioenergia (UDOP). Disponível em: $<$ http://www.udop.com.br/index.php?cod=1079735\&item=noticias $>$. Acesso em: 07/ mar/2012.

VILELA, Ednaldo de Souza; MENEZES, Emílio Araújo; JUNIOR, João Vollertt. (2000). Modelo de avaliação e medição das atividades dos hotéis: Mensuração e Gestão de custos para micro, pequenas e médias empresas. VII Congresso Brasileiro de Custos, Anais..., Recife, ago. 
Análise dos custos de produção dos agentes biológicos para controle de diatraea saccharalis em cana-de-açúcar: Um estudo de caso em laboratório de produção massal

Paulo Arnaldo Olak, Joice Amarante

VOLPE, Haroldo Xavier Linhares. (2009). Distribuição Espacial do parasitismo de Cotesia flavipes (Cameron, 1891) (Hymenoptera: Braconidae) em cana-de-açúcar, 2009. Dissertação de Mestrado. Faculdade de Ciências Agrárias e Veterinárias, Jaboticabal. Disponível em: <http://www.fcav.unesp.br/download/pgtrabs/ea/m/3512.pdf>. Acesso em: 14/abr/2011.

Data de Submissão: 08/07/2014

Data de Aceite: 02/04/2015 